\title{
revista internacjonal

\section{Análisis del impacto reciente de las remesas en el sector de la construcción en Colombia}

\author{
Analysis of the impact of remittances in the \\ construction industry in Colombia
}

\section{Catalina Vanessa Libreros Ángel ${ }^{1}$ y José Nabor Cruz Marcelo ${ }^{2}$}

${ }^{1}$ Licenciada en Economía, Profesora titular de asignatura en la Licenciatura de Economía, Facultad de Estudios Superiores de Aragón de la Universidad Nacional Autónoma de México, Estado de México, México.

${ }^{2}$ Doctor en Economía, Investigador Asociado C del Instituto de Investigaciones Económicas de la Universidad Nacional Autónoma de México, Ciudad de México, México.

Recibido: 20-10-2014

Aceptado: 13-1-2015

Correspondencia: Catalina Vanessa Libreros Ángel. Avenida Ángel Urraza, número 613, dpto. 4, CP: 03100, Colonia del Valle, Ciudad de México. México. E-mail: catalinavlibreros@ hotmail.com

(C) Revista Internacional de Estudios Migratorios. CEMyRI. UAL (España) 


\section{Resumen}

Introducción: A partir del año 2000 se inicia un proceso migratorio en Colombia, lo que progresivamente generó más de dos millones de colombianos residentes en el exterior en 2012, a la par, en dicho año Colombia se ubicó como el tercer país receptor de remesas de América Latina. Así mismo, se contempló en los Planes Nacionales de Desarrollo desde el 2002, una política de promoción gubernamental que consistió en encauzar las remesas a la adquisición de vivienda por parte de los propios migrantes y/o sus familias. En este sentido, las políticas públicas buscaron que las remesas cumplieran un rol funcionalista al impactar positivamente en la economía en su conjunto.

Método: Por lo anterior, se estima un modelo de Vectores Autorregresivos Irrestricto (UVAR por sus siglas en inglés) con datos trimestrales para el periodo 2004.1-2013.4, con el fin de analizar el impacto que han tenido las remesas de los trabajadores colombianos residentes en el exterior en el sector de la construcción.

Resultados: Se constata a través de la técnica econométrica que las remesas afectan de forma positiva e inmediata al menos durante tres trimestres a la tasa de crecimiento del producto del sector de la construcción (principalmente subsector edificador residencial) de Colombia.

Discusión o Conclusión: Al obtener los resultados, éstos indican que las políticas públicas han cumplido con su objetivo de dirigir las remesas hacia actividades económicas. En este caso, se encuentra que el sector de la construcción, y consecuentemente, la adquisición de vivienda en Colombia resultaron beneficiadas durante el periodo de estudio, debido a las políticas implantadas por el Gobierno.

Palabras Clave: sector de la construcción, remesas, migración, vector autorregresivo irrestricto, políticas públicas. 


\section{Abstract}

Introduction: From 2000 an immigration process begins in Colombia, so that by 2012 about two million Colombians are residing abroad, becoming the third largest recipient of remittances in Latin America. At same time, since 2002 these remittances were included in the National Development Plans, a government policy for development consisting in channeling remittances to the acquisition of housing for migrants themselves and / or their families. In this sense, public policies sought that remittances fulfill a functionalist role and have a positive impact in the economy as a whole.

Method: Therefore, an Unrestricted Vector Autoregressive (UVAR) model with quarterly data for the period 2004.1-2013.4 is used to analyze the impact that Colombian workers remittances' have had in the construction sector.

Results: It is found through the econometric technique that remittances positively affect immediately and at least three quarters the rate of growth of output in the construction (mainly residential builder subsector) of Colombia sector.

Discussion and Conclusion: The results indicate that public policies have met their goal of directing remittances to economic activities. Both, the construction sector and housing acquisition in Colombia were benefited by these governmental policies during the study period.

Keywords: construction industry, remittances, migration, unrestricted vector autoregression, public policies. 


\section{Introducción}

En las últimas dos décadas en Colombia se ha registrado un importante proceso migratorio, el cual se acentúa a partir del bienio de 1998-1999 al presentarse una fuerte crisis económica. Esto propició un incremento en la salida de colombianos para emplearse principalmente en Estados Unidos y España, por lo que para el año 2012, casi 4,5\% del total de la población residía fuera del país, a la par, Colombia se ubicó como el tercer país captor de remesas de América Latina, al recibir un poco más de cuatro mil millones de dólares.

Por lo anterior, ante el constante incremento de migración y recepción de remesas durante los últimos quince años, el Gobierno de la República de Colombia a partir del 2002 contempló la incorporación de un conjunto de políticas públicas en los Planes Nacionales de Desarrollo, con el objetivo de incentivar que el flujo de las remesas se dirigieran a la adquisición de bienes inmuebles por parte de los migrantes y sus familias. Por lo tanto se llevaron a cabo tanto ferias internacionales de vivienda en Europa y Estados Unidos, así como una expansión en los planes de financiamiento y una reducción de la tasa de interés de créditos hipotecarios, entre otro tipos de programas e incentivos. Lo anterior se realizó bajo la concepción de que tanto el sector de la construcción como el subsector de la vivienda fungieran como factores importantes en el fomento al crecimiento económico, debido al encadenamiento productivo que teóricamente generan dichas actividades.

Ante dicho contexto, la hipótesis de esta investigación supone que el flujo de remesas es un factor que ha impactado de forma positiva en la dinamización del producto del sector de la construcción, lo que de acuerdo a la concepción teórica de la Comisión Económica para América Latina y el Caribe (CEPAL) se define como un rol funcionalista, ya que se han incentivado las actividades productivas —en este caso, la expansión del sector de la construcción tanto de obras civiles como edificaciones- a partir de que el Gobierno ha coadyuvado a través de políticas públicas, la adquisición de bienes inmuebles en Colombia por parte de los residentes nacionales en el exterior. Lo anterior se comprueba por medio de la estimación de un modelo de Vectores Autorregresivos Irrestricto (UVAR) para el periodo 2004.1-2013.4, el cual es estadísticamente significativo. 
En general, se resalta que un conjunto de factores diversos que se presentaron en este periodo de tiempo, tales como: el aumento de la migración y consecuentemente del flujo de las remesas, las políticas públicas implementadas y el propio crecimiento de la economía, coadyuvaron a que el sector de la construcción en Colombia reportara un fuerte dinamismo durante este periodo.

Aunque el debate sobre el impacto de las remesas que una economía recibe a lo largo de un cierto periodo de tiempo, se ha centrado sobre si éstas pueden $\longrightarrow \mathrm{O}$ nocoadyuvar al crecimiento y desarrollo económico; bajo dicho contexto tanto Brown (2006) como Gapen, Barajas, Chami, Montiel, y Fullenkamp (2009), señalan que es indudable que las remesas constituyen un papel fundamental en los países en vías de desarrollo, puesto que una franja de su población percibe ingresos extraordinarios, los cuales pueden mejorar, aunque sea de forma marginal sus percepciones mensuales, que teóricamente significaría una mejora en la calidad de vida, sin embargo, dichos autores no comprueban empíricamente la relación del flujo de remesas con el crecimiento económico, por lo anterior, habrá que examinar el papel que juegan las remesas hacia el interior de la economía receptora, por ello es importante empezar con algunas definiciones de dichos ingresos.

"Las remesas, se entienden, de modo generalizado, como las proporciones de ingreso de los migrantes internacionales con residencia temporal o permanente en el país donde trabajan que son transferidas desde éste al lugar de origen, en algunos casos también incluyen las jubilaciones pagadas a los trabajadores migrantes que retornan al país de nacimiento" (CEPAL, 2008: 190).

Desde un enfoque financiero, se tiene que: "Se definen como una transferencia unilateral entre residentes de dos países distintos que no tienen por objeto el pago de un bien o servicio, por lo cual se supone que ambos son familiares, sino contribuir a la manutención del o los receptores" (CEPAL, 2008: 190).

Así mismo, otra consideración para el flujo monetario que envían los residentes en el exterior es: "Las remesas pueden jugar un papel importante como atenuador de la pobreza, especialmente en aquellas economías cuyas bajas tasas de crecimiento han dificultado la aplicación de políticas de gasto social" (Urrutia, 2003: 5). 
Ahora bien, en la literatura especializada en el tema de remesas, se pueden ubicar tres grandes grupos de análisis. En primer lugar, se presenta el enfoque estructuralista (desarrollado a lo largo de la década de los ochentas) cuyo objetivo se centró en examinar los efectos económicos y sociales de la emigración y de las remesas en las entidades de origen, entre sus conclusiones se destaca la presencia de círculos viciosos que perpetúan las condiciones de atraso estructural al interior de las comunidades expulsoras de trabajadores. Sin embargo, al presentarse el cambio de paradigma en la política económica a finales de los años ochenta y principios de la siguiente década, el nuevo enfoque que predominó sobre esta temática fue el marco teórico funcionalista, bajo el cual se establecía tres funciones básicas de cómo se debieran encauzar las remesas: a) coadyuvar a la inversión productiva, b) el efecto multiplicativo de las mismas y c) la utilización de las remesas como un mecanismo en la búsqueda de la reducción de la desigualdad social.

Finalmente, a partir de la primera década del nuevo siglo, se presenta un nuevo enfoque desarrollado por Organismos Internacionales - a saber Banco Mundial, Fondo Monetario Internacional y Banco Interamericano de Desarrollo, entre otros- cuyo punto de inflexión tiene como antecedente la cumbre del denominado G8 (Alemania, Canadá, Estados Unidos, Francia, Italia, Japón, Reino Unido y Rusia) en Sea Island 2004, en el cual estos países acordaron cooperar con dichos organismos para encauzar las remesas, a través de programas gubernamentales, para financiar la creación de pequeñas y medianas empresas, además de formar capital productivo y humano, tal como lo expone Martínez (2008).

Otro enfoque respecto a las remesas es acerca de una relación contracíclica o procíclica al interior de una economía de acuerdo a las motivaciones que generen el envío de remesas al país receptor: altruismo o inversión, tal y como lo consideran Lucas y Stark (1985). La relación contracíclica que es respaldada por algunos autores como Chami, Fullenkamp y Jahjah (2005), Ratha (2005), Bouhga-Hagbe (2006), Sayan (2006), Carvajal y de Jesús (2011), se fundamenta en la actitud altruista de los emigrantes, ya que en tiempos de recesión incrementarían los envíos de remesas a sus familias con el fin de cubrir las necesidades básicas, por lo que, estos representarían una fuente importante de ingresos que se reflejarían en una mayor capacidad de adquisición de bienes de consumo, así: "Las remesas se destinan principalmente a financiar el gasto 
corriente de los hogares, seguido por gastos en educación y salud, lo cual tiene un impacto directo y otros marginales sobre las variables sociales y económicas de cada país" (Uribe, 2005: 1).

Por su parte, Montoya, López, Arboleda, Ramírez, y Viana-Casas (2010) analizan el proceso de envío de remesas a Colombia en el periodo 2000-2009, el cual afirman que comenzó en principio como un fenómeno contracíclico, pero terminó en uno procíclico, a través de las decisiones de inversión como la adquisición de activos y formación de pequeños negocios.

Ahora bien, revisamos algunos estudios empíricos que señalan la relación de las remesas y el sector de la construcción para el caso de Colombia, en primer lugar Khoudour-Castéras (2007) al analizar — de forma descriptiva— el destino de las remesas, encuentra que el sector de la construcción en Colombia se ha beneficiado por el ingreso de las mismas, debido a la compra de vivienda realizada por las familias de los emigrantes, así como mediante la inversión directa de colombianos residentes en el exterior.

Por su parte, Montoya et al. (2010) concluyen que el envío de remesas por inversión busca la rentabilidad a través de la creación de nuevos negocios o compra de cualquier tipo de activos. Así mismo, Zapata (2011) ahondó en dicha temática, al estudiar el caso específico de trabajadores de origen colombiano que residían en Londres, Inglaterra, concluye que el envío de remesas aumentó después de 2005, además los trabajadores conocieron los programas oficiales que tenían como incentivo la compra de vivienda en su país, sin embargo, este no fue el único mecanismo de transferencias de remesas para dicho fin, sino que los trabajadores enviaron sus ingresos directamente a sus familiares, tanto para realizar remodelaciones como nuevas edificaciones.

En el contexto internacional encontramos los siguientes documentos: McBride (2007) en el caso de El Salvador, a través de analizar la Encuesta de Hogares para Propósitos Múltiples 2006, señala que 74\% de las remesas son destinadas al sector de la construcción, por lo tanto, el autor destaca que efectivamente las familias que cuentan 
con ingresos extraordinarios provenientes de remesas, han mejorado significativamente las condiciones materiales de sus hogares.

Para la economía ecuatoriana Torres (2011) expone que a partir del año 2000 el desarrollo económico del país ha estado vinculado al sector de la construcción, así mismo señala que en 2007 dicha rama fue la quinta en importancia en términos de su contribución al Producto Interior Bruto (PIB) nacional y la cuarta respecto al empleo, para el periodo 2000-2009 encuentra que la participación promedio del Valor Agregado Bruto (VAB) de la construcción fue de 8,6\% en el PIB nacional. El autor concluye que el auge del sector de la construcción en Ecuador se debe a los beneficios derivados de la dolarización, y a las remesas de los migrantes. Cabe señalar que estos trabajos no ocupan técnicas econométricas para establecer la relación que se presenta entre ambas variables.

Por otro lado, entre los estudios econométricos que analizan la evolución del sector de la construcción y/o vivienda, en la economía colombiana en primer lugar, se encuentran los trabajos de Herrera (1988) con un periodo de 1967-1987 y Cárdenas y Bernal (1997) para un periodo de 1988-1995, ambos tienen como objetivo central, estimar los determinantes de la vivienda en Colombia en cada uno de los periodos a través de modelos de oferta y demanda. Por su parte Díaz, Gaitán, Piraquive, Ramírez, y Roda (1993) para el periodo 1950-1991 encuentran una asociación estadísticamente significativa entre el PIB total y el PIB de la construcción. Asimismo, a través de la causalidad en el sentido de Granger los autores dan cuenta que el sector de la construcción responde a los cambios del PIB total y no en el sentido contrario.

En segundo lugar, Cárdenas, Cadena y Quintero (2004), a través de un modelo de oferta y demanda que incluye un sistema de ecuaciones simultáneas, señalan que los créditos, la tasa de interés hipotecaria, la tasa de desempleo, las remesas y los flujos de capital exterior fungen como posibles determinantes de la demanda por construcciones. Los resultados indican que la actividad constructora en Colombia por el lado de la oferta está determinada por los costos asociados a la actividad y por el lado de la demanda por el financiamiento y los ingresos de los hogares. A su vez, Cárdenas y Hernández (2006) analizan el aporte del sistema financiero en el sector de la construcción de vivienda en Colombia y estiman la forma reducida de un modelo de oferta y demanda de residencias 
en el periodo 1985.1-2005.1 para encontrar los determinantes de la construcción. Sus resultados indican que el otorgamiento de créditos tiene un impacto positivo sobre la actividad constructora, mientras que la tasa de interés hipotecaria tiene un efecto negativo sobre ésta.

La Cámara Colombiana de la Construcción, CAMACOL (2008) analiza el dinamismo del sector de la construcción y su efecto en la economía colombiana. Para ello, realizan tres estimaciones: a) modelo de regresión lineal para el periodo 1985.12007.4, b) modelo Autorregresivo de Media Móvil (ARMA) y c) modelo de Vectores Autorregresivos (VAR), este último para pronosticar el comportamiento del sector de la construcción a junio de 2008. Establecen el comportamiento de las licencias aprobadas de construcción (residencial y no residencial) y sus determinantes. Los resultados señalan que los créditos hipotecarios y la tasa de interés hipotecaria tienen un mayor impacto sobre las licencias y en menor medida en el desempleo.

En general, consideramos que las políticas públicas —explicadas a detalle en el apartado 2.1.2 - que se implementaron en Colombia a partir del 2002 se pueden ubicar principalmente bajo el enfoque funcionalista de las remesas, ya que suponemos que coadyuvaron a expandir la inversión productiva, principalmente en el sector de la construcción, así como al efecto multiplicativo de las mismas. Además suponemos que el ingreso por remesas se encausaron no solo de forma exclusiva al motivo altruismo sino también al de inversión, al reportarse un fuerte dinamismo en el sector de la construcción. La anterior revisión de literatura nos permite contextualizar la hipótesis de estudio, la cual, a través de la estimación econométrica nos sugiere la relación existente entre las remesas y el PIB del sector de la construcción para el caso colombiano.

\section{Método}

\subsection{Sujetos}

\subsubsection{Migración, remesas y crecimiento económico}

De acuerdo a cifras reportadas por el Ministerio de Relaciones Exteriores (2014), Colombia se ha caracterizado por presentar movilidad de población con tres grandes olas migratorias, la primera en la década de los años sesenta mayoritariamente dirigida hacia Estados Unidos, la de los años ochenta a Venezuela y la de finales de los 
años noventa y de la primera década del 2000 hacia España. ${ }^{1}$ Esta última oleada se generó bajo el contexto de crisis económica en el país, así como otros factores entre los que destacan: la violencia e inseguridad, la inestabilidad política y social del país, así como una alta tasa de desempleo $(20,1 \%$ del total de la Población Económicamente Activa, PEA).

Sin embargo, el fenómeno migratorio se destaca no sólo para Colombia, sino para el resto de países latinoamericanos, de acuerdo a los datos sobre migración y remesas del Banco Mundial (2011), para el año 2010 se reportaron alrededor de 215 millones de migrantes en todo el mundo, de los cuales más de 30,2 millones de ciudadanos latinoamericanos y caribeños $-5,2 \%$ en relación a la población total de la región- viven fuera de su entidad de origen. De acuerdo a la Organización Internacional para las Migraciones, OIM (2013), entre los países de la región, México reporta el mayor número de migrantes, con 11.859.200 de personas, en segundo lugar se encuentra Colombia con 2.122.100, finalmente se ubica a Brasil con 1.367.100 migrantes.

En cuanto a las remesas, de acuerdo al informe del Fondo Multilateral de Inversiones, FOMIN (2013), se presentó una tendencia creciente en las mismas a partir del año 2001, cuando América Latina y el Caribe pasaron de captar US\$ 21.900 millones a US\$ 61.276 millones en 2012. Al revisar el flujo de divisas por economía, México se constituyó en 2013 como el país de mayor captación al recibir US\$ 22.446 millones, en segundo lugar se ubicó Guatemala con US\$ 4.782 millones, finalmente, en tercer lugar se colocó Colombia, al recibir US\$ 4.073 millones.

Por su parte, al revisar las cifras de la Encuesta Trimestral de Remesas del Banco de la República de Colombia (2014) en 2013 los tres principales países de origen de remesas fueron: Estados Unidos (US\$ 1.527 millones), España (US\$ 936 millones) y Venezuela (US\$ 495 millones) dichos montos representaron 73\% del total de remesas captadas en dicho año.

\footnotetext{
${ }^{1}$ Los registros del Ministerio de Empleo y Seguridad Social de España (2014) reportan que para el año 2000 el número de colombianos que se encontraban registrados y reconocidos por el Gobierno español eran 24.702, mientras que para el año 2007 esta cifra se ubicó en 254.301 (6,4\% del total de los extranjeros residentes en España) lo que representa el dato más alto del periodo. Sin embargo para 2013, los colombianos contabilizados de forma oficial se redujeron a 162.374 (3,3\% del total de extranjeros).
} 
Esta expansión reciente de los flujos de las remesas ha podido representar un posible efecto multiplicativo en diversos ámbitos de la economía:

"El aumento masivo de remesas en Colombia en los últimos años ha contribuido a mejorar de manera significativa las condiciones de vida de las familias receptoras, gracias a un incremento del poder de compra que les ha permitido tener acceso a un abanico más grande de productos de consumo y de servicios de salud y educación" (Khoudour-Castéras, 2007: 148).

Al comparar la evolución de la tendencia tanto del flujo de las remesas como de la tasa de crecimiento del PIB total —expuestas en la figura 1- se observa que a partir de la crisis económica y consecuente contracción del PIB, 4,3\% en 1999, no sólo la migración se aceleró, sino también el ingreso por remesas, las cuales acompañaron la trayectoria ascendente del PIB reportada en 2000-2008.

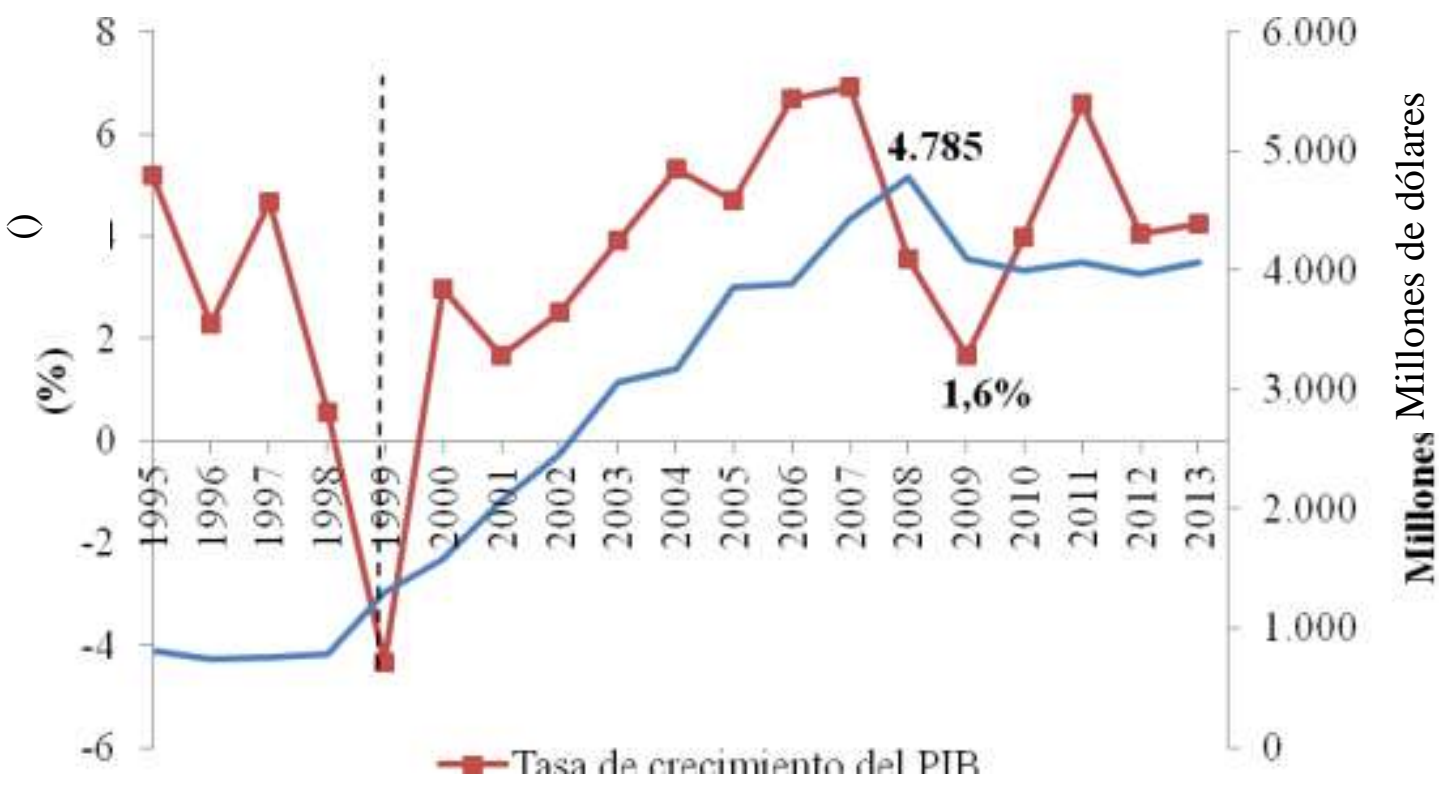

Figura 1. Evolución de la tasa de crecimiento del PIB total (eje izquierdo) y el flujo de las remesas en Colombia (eje derecho), 1995-2013

Fuente: Elaboración propia a partir de los datos del Banco de la República (2014). Agradecemos a Liset Sánchez Toledo por el procesamiento de la base de datos. 
Por lo tanto, ya que ambas variables exhiben trayectorias de crecimiento dinámico durante el periodo revisado se puede contextualizar su relación a través de la hipótesis del comportamiento contracíclico de las remesas, sugerido por Lucas y Stark (1985) —ya mencionados en la introducción — que ante una crisis económica los migrantes envían dinero a sus familias por motivos altruistas, con el fin de contribuir a mejorar las condiciones de vida de los hogares receptores.

\subsubsection{El sector de la construcción en Colombia}

De acuerdo a cifras del Departamento Administrativo Nacional de Estadística, DANE (2014) los sectores con las tasas de crecimiento promedio anual más dinámicas durante el periodo 2003-2007, fueron el de la construcción (9,5\%), los servicios de transporte $(9,3 \%)$, el comercio $(7,1 \%)$ y la industria $(6,6 \%)$. Así, como se ha mencionado anteriormente, el sector de la construcción se mostró como la actividad de mayor crecimiento, a pesar de la reducción del PIB por la crisis económica mundial 2008-2009, tendencia que se prolongó hasta 2013, tal como se reporta en la tabla 1.

Tabla 1. Tasa de crecimiento del PIB total y ramas de actividad económica, 2001-2013 (promedio anual, \%)

\begin{tabular}{lcccc}
\hline \multicolumn{1}{c}{ Ramas de Actividad Económica } & $\mathbf{2 0 0 3 -}$ & $\mathbf{2 0 0 7}-$ & $\mathbf{2 0 0 1 -}$ & $\mathbf{2 0 1 3}$ \\
& $\mathbf{2 0 0 7}$ & $\mathbf{2 0 0 9}$ & $\mathbf{2 0 1 3}$ & \\
\hline Agricultura, ganadería, caza, silvicultura y pesca & 3,0 & $-0,5$ & 2,4 & 5,2 \\
Explotación de minas y canteras & 1,7 & 10,2 & 5,1 & 4,9 \\
Industrias manufactureras & 6,6 & $-1,8$ & 2,8 & $-1,2$ \\
Suministro de electricidad, gas y agua & 4,1 & 1,2 & 3,2 & 4,9 \\
Construcción & 9,5 & 7,0 & 8,0 & 9,8 \\
Comercio, reparación, restaurantes y hoteles & 7,1 & 1,4 & 4,7 & 4,3 \\
Transporte, almacenamiento y comunicaciones & 9,3 & 1,6 & 5,7 & 3,1 \\
Establecimientos financieros, seguros, actividades & & & & \\
inmobiliarias y servicios a las empresas & 5,7 & 3,8 & 4,8 & 4,6 \\
Actividades de servicios sociales, comunales y & & & & \\
personales & 4,2 & 3,5 & 3,7 & 5,3 \\
PIB total & & & & \\
\hline
\end{tabular}

* Las variables con las que se calcularon las tasas de crecimiento están expresadas en millones de pesos constantes del año 2005.

Fuente: Elaboración propia a partir de los datos del DANE (2014). 
Ahora bien, al retomar la metodología que implementa CAMACOL el PIB de la construcción se puede dividir en dos subsectores. El primero relacionado con el subsector de edificaciones; en donde se agrupan las construcciones residenciales (tanto rurales como urbanas), edificios no residenciales, reparación de edificios y mantenimientos, y alquiler de equipos de construcción. El otro subsector es el de obras civiles, que abarca: la construcción de carreteras, vías férreas, puertos y drenajes. Desde finales del 2004 la actividad en obras civiles ha aumentado, en gran parte debido al incremento en los planes de inversión en infraestructuras vial y de servicios públicos.

En el contexto de los hechos estilizados, el sector de la construcción puede constituirse como un motor para el crecimiento económico, como lo plantea CAMACOL (2011) considera que dicho sector se caracteriza por su elevado nivel de encadenamiento con otros sectores productivos ya que tiene la capacidad de actuar como un multiplicador de la producción y del empleo. Por lo anterior, se implementaron políticas públicas que estimularon y fortalecieron a dicho sector en el periodo de estudio. En el año 2002, el Gobierno del Presidente Álvaro Uribe Vélez a través del Departamento Nacional de Planeación (DNP) decidió promover el llamado "Plan Nacional de Desarrollo: Hacia un Estado Comunitario, 2002-2006”, el cual tenía entre sus objetivos impulsar el crecimiento económico sostenible y la generación de empleo:

"El Gobierno centrará la recuperación económica en el sector de la vivienda y la construcción. Para ello ha diseñado una estrategia comprensiva que incluye un impulso denodado a la vivienda de interés social y un paquete de estímulos tendientes a reactivar el crédito hipotecario y, por esta vía, la construcción de vivienda para estratos medios y altos” (DNP, 2003: 103).

Desde el 2005, CAMACOL con el respaldo del Gobierno de la República a través de diversas entidades como el Ministerio de Relaciones Exteriores de Colombia y su programa "Colombia Nos Une"; Proexport Colombia, Ministerio de Vivienda, Ciudad y Territorio; y los consulados de Colombia en las ciudades en las que se lleva a cabo la feria internacional "Donde vivir e invertir en Colombia", la cual por primera vez se realizó en 2005 en Miami y Nueva York; posteriormente abril de 2007 en Madrid y en 2008 en Londres, con el fin de concentrar la oferta y la demanda de proyectos inmobiliarios en Colombia e impulsar las distintas alternativas de financiamiento que 
ofrece el mercado, para facilitar la decisión de compra de los colombianos residentes en el exterior. En general, la realización de este evento ha tenido como objetivo que los colombianos inviertan sus remesas en la adquisición de un inmueble ya sea para su familia, o como una inversión que represente una fuente de ingresos futuros.

Posteriormente el Gobierno del Presidente de la República Juan Manuel Santos Calderón, de acuerdo al lineamiento denominado "Crecimiento Sostenible y Competitividad" del Plan Nacional de Desarrollo 2010-2014 "Prosperidad para todos", establece la dinamización de sectores que denomina como "locomotoras": el sector agropecuario, el sector minero-energético, nuevos sectores basados en la innovación, la vivienda y la infraestructura, estos dos últimos dadas sus características fueron considerados por el Gobierno como posibles sectores líderes en el crecimiento y la generación de empleo a través del impacto directo e indirecto que tienen sobre el resto de la economía:

"La construcción constituye una apuesta para aprovechar el incremento en la demanda de vivienda que se genera con el dinamismo económico, para impulsar la generación de empleo, especialmente en las zonas urbanas del país. Así mismo, el sector de la vivienda, dados sus eslabonamientos con múltiples y diversas actividades económicas, tiene el potencial de dinamizar la economía e impulsar el crecimiento y la generación de empleo de manera casi transversal" (DNP, 2010: 52).

Así mismo, el Gobierno colombiano implementó el Plan de Impulso al Empleo y la Productividad (PIPE) a través del Ministerio de Hacienda y Crédito Público el 13 de abril de 2013. Dicho plan se concentra en dos medidas: la primera de tipo transversal, que impacta positivamente todos los sectores de la actividad económica y la segunda, con disposiciones específicas en sectores de alto impacto en la generación de valor agregado y empleo. En cuanto a las últimas, se introdujo un subsidio a la tasa de interés para créditos de edificaciones residenciales de clase media, por lo que se redujo la tasa de interés de $12,5 \%$ a $7 \%$ anual -el 2,5\% subsidiado por el Gobierno y el resto por el sector bancario-, así como la construcción de 100 mil viviendas apoyadas en subsidios directos. En cuanto a la infraestructura de obra civil se planteó aportar 711 mil millones de pesos colombianos (aproximadamente 270 millones de euros) para la finalización de 
las carreteras que ya estaban en marcha, con ello se esperaba estimular proyectos en infraestructura que incrementarían la conectividad entre las regiones.

\subsection{Análisis Estadístico}

Después de haber realizado una puntual revisión del marco teórico, el estado del arte y de los principales hechos estilizados de las variables consideradas, en este apartado se exponen algunas técnicas estadísticas y econométricas que coadyuvan a comprobar nuestra hipótesis de estudio. En primer lugar, se examina la relación entre la tasa de crecimiento de las remesas $(\Delta \mathrm{Rem})$ y la tasa de crecimiento del PIB total $(\Delta \mathrm{PIB})$ a través de la prueba de causalidad en el sentido de Granger $^{2}$ con datos anuales durante el periodo 1995-2013, esto con el fin de examinar el tipo de relación estadística que existe entre ambas variables.

Tabla 2. Prueba de causalidad en el sentido de Granger de la tasa de crecimiento de las remesas y de la del PIB total, 1995-2013

\begin{tabular}{ccc}
\hline Hipótesis nula & Estadístico $\mathbf{F}$ & Probabilidad \\
\hline$* \Delta$ Rem no causa a $\Delta$ PIB & 6,365 & $0,016(3)$ \\
$\Delta$ PIB no causa a $\Delta$ Rem & 1,625 & $0,258(3)$ \\
\hline
\end{tabular}

Nota: $\Delta \mathrm{Rem}=$ Tasa de crecimiento del flujo de las remesas; $\Delta \mathrm{PIB}=$ Tasa de crecimiento del PIB total; * indica rechazo de la hipótesis nula y, por tanto, existe causalidad en el sentido de Granger al 5\% de significancia; entre paréntesis el número de rezagos. Las variables así especificadas son estacionarias. Los resultados de las pruebas de raíces unitarias aplicadas se encuentran en la tabla 4 del anexo estadístico. Fuente: Elaboración propia a partir de los datos del Banco de la República (2014).

Los resultados indican que existe una relación unidireccional, es decir, que el crecimiento de las remesas causa (ó ayuda a predecir) el crecimiento del PIB total, y no en el sentido contrario, por lo tanto, se puede identificar la existencia de un efecto de arrastre de las remesas a favor de la tasa de crecimiento del PIB (ver tabla 2). Dicha conclusión va acorde con la tesis expuesta por Fajnzylber y López (2006) quienes consideran que las remesas tienen un efecto multiplicador sobre el crecimiento económico al contribuir a incrementar el consumo, la inversión o el propio producto agregado. En general esta prueba nos ayuda a confirmar las inferencias realizadas en

\footnotetext{
${ }^{2}$ Tanto Granger (1969) y Sims (1980) deducen el sentido de la causalidad cuando los valores retardados de una variable $x_{\mathrm{t}}$, tienen poder explicativo en una regresión de una variable $y_{\mathrm{t}}$ en los valores retardados de $y_{\mathrm{t}} \mathrm{y} x_{\mathrm{t}}$, véase Greene (1999).
} 
otras investigaciones sobre el rol positivo que desempeñan los ingresos enviados por los migrantes hacia sus familias en su país de origen.

En segundo lugar se estima, a través del coeficiente de correlación, el tipo de relación entre ambas series, los resultados expuestos gráficamente en la figura 7 del anexo estadístico nos permiten identificar una asociación negativa entre ambas variables — cabe aclarar que esto no denota causalidad entre las mismas sino la relación existentes entre éstas-, lo que significa que hay una relación inversa. Es decir, se puede afirmar que un aumento en el nivel de remesas tendería a compensar contracciones en el PIB total, por otro lado, una expansión del PIB, puede implicar una disminución en los envíos monetarios de los migrantes hacia el país.

Si bien no es el objetivo central del documento, al analizar la relación entre el flujo de remesas con la tasa de crecimiento del PIB, se comprueba la hipótesis del enfoque funcionalista, es decir, el efecto multiplicativo que se presenta gracias al ingreso monetario enviado por los residentes en el exterior.

Después de haber establecido de forma estadística, la relación entre los ingresos monetarios provenientes de los migrantes y el Producto Interno Bruto agregado de la economía colombiana, ahora se calcula la correlación entre las tasa de crecimiento de las remesas $(\Delta \mathrm{Rem})$ y la del PIB del sector de la construcción $(\Delta \mathrm{Co})$ con datos trimestrales constantes de 2004.1-2013.4, esto con el fin de comprobar el impacto de la implementación de diversas políticas públicas — señaladas en el apartado anterior- en el producto del sector de la construcción.

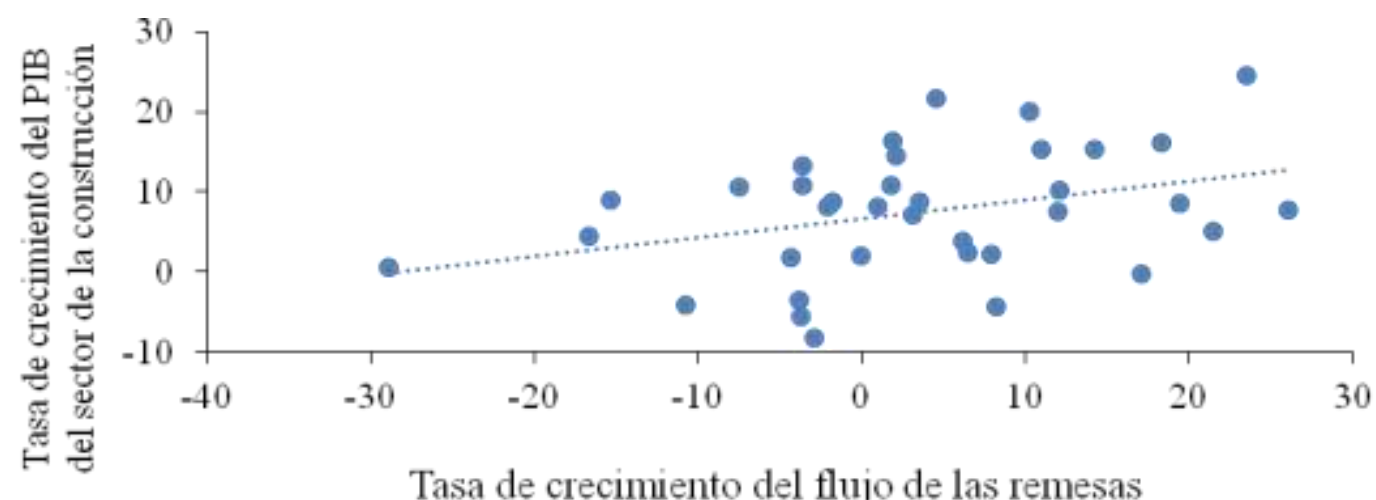

Tasa de crecimiento del flujo de las remesas 


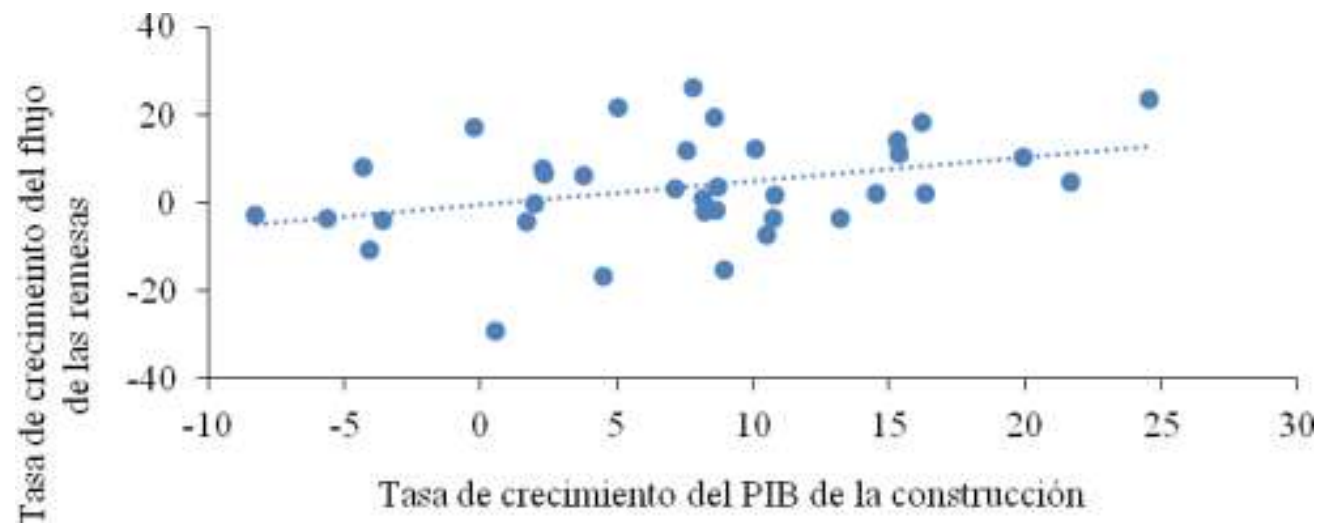

Figura 2. Diagrama de dispersión: tasa de crecimiento del PIB del sector de la construcción $v s$ tasa de crecimiento de las remesas, 2004.1-2013.4

Fuente: Elaboración propia a partir de los datos de CAMACOL y el Banco de la República (2014).

Los resultados indican que la correlación es positiva, lo que significa una relación directa entre ambas variables. Por tanto, esto sugiere que el aumento en los ingresos por remesas en el periodo de estudio, ha sido un fuerte incentivo para que los migrantes hayan canalizado dichos recursos hacia la inversión local a través de la adquisición de activos fijos en Colombia. De ahí, se comprueba que las políticas que los últimos gobiernos colombianos han implementado resultaron beneficiosas de forma significativa a la dinamización del sector de la construcción.

No obstante, es de nuestro interés estudiar el comportamiento que han tenido las remesas en el sector de la construcción, ya que como se ha mencionado a lo largo de este trabajo, el flujo del dinero enviado por los trabajadores colombianos en el exterior, comenzó a incrementarse en los primeros años de la década de los 2000 debido al fuerte proceso de migración que se registró en Colombia. Por lo tanto, a continuación se expone la estimación econométrica realizada para comprobar la hipótesis de esta investigación.

\subsubsection{Estimación del Modelo de Vectores Autorregresivos Irrestricto (UVAR)}

Se estima un modelo de Vectores Autorregresivos Irrestricto (UVAR) con impulsos generalizados, en el que se examina la relación existente entre la tasa de

\footnotetext{
${ }^{3} \mathrm{r}=0,35 ; \mathrm{t}=2,20$
} 
crecimiento de las remesas y la del PIB del sector de la construcción, así como la sensibilidad de éstas para el periodo considerado. Cabe mencionar que los modelos VAR son ateóricos, lo que significa que no tienen una teoría tras su formulación, Greene (1999). Por tanto, las variables que se consideran, corresponden a la intuición de la línea causal que establece el modelador, sobre los efectos de trasmisión entre las variables, en base a los análisis previos que haya realizado

El periodo de estimación es 2004.1-2013.4, en virtud que a partir de 2004 tanto el flujo de remesas como el PIB de la construcción reportaron una tendencia ascendente. De acuerdo con los criterios convencionales - Error Final de Predicción, Akaike, Schwarz, Hannan-Quinn y $\mathrm{LR}^{-}$se especificó un UVAR con 4 rezagos, para ambas variables. Además se incorporó una constante y una dummy - la cual se emplea para captar periodos u observaciones atípicas (outlayers) —, que asociamos a los periodos en que se presentó una leve desaceleración en el PIB del sector de la construcción (para los periodos de 2008.4 y 2010.3). A continuación se presenta la ecuación del modelo econométrico estimado:

$$
y_{t}=d_{t}+C_{y_{t-i}}+u_{t}
$$

Donde: $y_{t}$ es un vector de variables endógenas, $d_{t}$ es un vector de componentes determinístico (constante y dummy), $u_{t}$ es el vector de innovaciones.

Así pues, con la finalidad de probar la pertinencia de la estimación econométrica se analizan las pruebas de correcta especificación ${ }^{4}$ y la simulación del sistema (figuras 5 y 6) por lo que se puede constatar que el modelo es estadísticamente significativo. Los resultados muestran que el UVAR es estable, y por lo tanto es adecuado para realizar análisis de sensibilidad que se hace a través de las pruebas de impulso-respuesta y de descomposición de varianza, Loría (2007: 304). De ahí, que las pruebas de causalidad de Granger, de impulso-respuesta y de descomposición de varianza complementan el análisis de los modelos VAR, tal como lo señalamos en el apartado de los resultados que obtenemos con dicha modelación.

\footnotetext{
${ }^{4} \lambda \max =0,83 ;$ Normalidad (Urzúa) $=10,34(0,32) ; \operatorname{LM}(11)=7,43(0,11) ;$ White N.C = 49,27(0,65); White $(\mathrm{c})=$ N.D.
} 


\section{Resultados}

Un factor relevante dentro de la correcta especificación del UVAR es la prueba de causalidad en el sentido de Granger, que indica que el crecimiento de las remesas causan (o propician) el crecimiento en el PIB del sector de la construcción, con lo cual podríamos corroborar la pertinencia del enfoque teórico de esta investigación así como la comprobación de los efectos de las políticas económicas del Gobierno de la República para favorecer la inversión en este sector a través de la canalización de los flujos de las remesas al mismo.

Tabla 3. Prueba de causalidad en el sentido de Granger de la tasa de crecimiento del flujo de las remesas y la del PIB del sector de la construcción, 2004.1-2013.4

\begin{tabular}{ccc}
\hline Hipótesis nula & Estadístico $\chi^{\mathbf{2}}$ & Probabilidad \\
\hline$* \Delta$ Rem no causa a $\Delta$ Co & 11,309 & $0,023(4)$ \\
$\Delta$ Co no causa a $\Delta$ Rem & 0,423 & $0,980(4)$ \\
\hline
\end{tabular}

Nota: $\Delta$ Rem $=$ Tasa de crecimiento del flujo de las remesas; $\Delta$ Co $=$ Tasa de crecimiento del PIB del sector de la construcción; * indica rechazo de la hipótesis nula y, por tanto, existe causalidad en el sentido de Granger al 5\% de significancia; entre paréntesis el número de rezagos. Las variables así especificadas son estacionarias. Los resultados de las pruebas de raíces unitarias aplicadas se encuentran en la tabla 4 del anexo estadístico.

Fuente: Elaboración propia a partir de los datos de CAMACOL y el Banco de la República (2014).

El análisis impulso-respuesta es un instrumento útil para evaluar la sensibilidad y congruencia de las variables que especificamos en el modelo, ya que indica la respuesta temporal de las series ante shocks específicos de las mismas, en este caso ( $\Delta$ Rem y $\Delta \mathrm{Co}$ ). Así, la estimación que se obtiene con el UVAR suscita que las remesas han beneficiado al sector de la construcción, tal como lo señala la hipótesis de esta investigación.

Los resultados de los impulsos-respuesta generalizados —que es la metodología de Pesaran y Shin (1998), y se sugiere aplicarla cuando no se tiene claro el canal de trasmisión de los choques entre las variables, Loría (2007: 312)— (figuras 3 y 4) que se realizan para observar los impactos que causan las remesas sobre el producto del sector de la construcción y viceversa, muestran el efecto positivo e inmediato durante tres trimestres del choque del crecimiento del flujo de las remesas al crecimiento del PIB del sector de la construcción, así como durante dos trimestres en el sentido inverso. Este resultado sugiere que existe un vínculo entre las remesas y el sector de la construcción, 
bajo el contexto de las políticas gubernamentales que han actuado dentro de un esquema de canalización de los flujos de remesas hacia dicho sector, además de que podemos inferir que efectivamente el dinero enviado por los migrantes no sólo es generado por el motivo altruismo, sino por el de inversión, ya que las remesas en cierta medida coadyuvaron al fuerte dinamismo del sector de la construcción, principalmente por el subsector de edificaciones que se registraron durante el periodo estimado.

Al revisar los datos de la CAMACOL (publicadas 3 de abril 2014), las licencias aprobadas en edificaciones de viviendas de interés social —medidas en metros cuadrados_-, fueron en promedio 135.575 en el primer trimestre de 2004, mostraron una amplia expansión puesto que para el último trimestre de 2013, los metros cuadrados aprobados fueron 515.509, es decir el número de viviendas de interés social prácticamente se quintuplicó en este periodo. Pero no sólo las edificaciones reportaron esta dinámica, las obras civiles también registraron un alto crecimiento, ya que el rubro denominado "obras nuevas" en el primer trimestre de 2004 resultaron 1.856 .458 pero para el cuarto trimestre de 2013 esta cifra aumentó a 3.014.595 de metros cuadrados aprobados para construcción. Por lo tanto, consideramos que el impacto de la adquisición de vivienda en el producto del sector de la construcción se presenta por dos vías, la primera, por la edificación de las casas de interés social y la segunda, por las obras civiles, principalmente en servicios públicos que requieren estos nuevos bienes inmuebles, por lo tanto, se puede inferir en un amplio efecto multiplicativo hacia el interior del sector de la construcción.

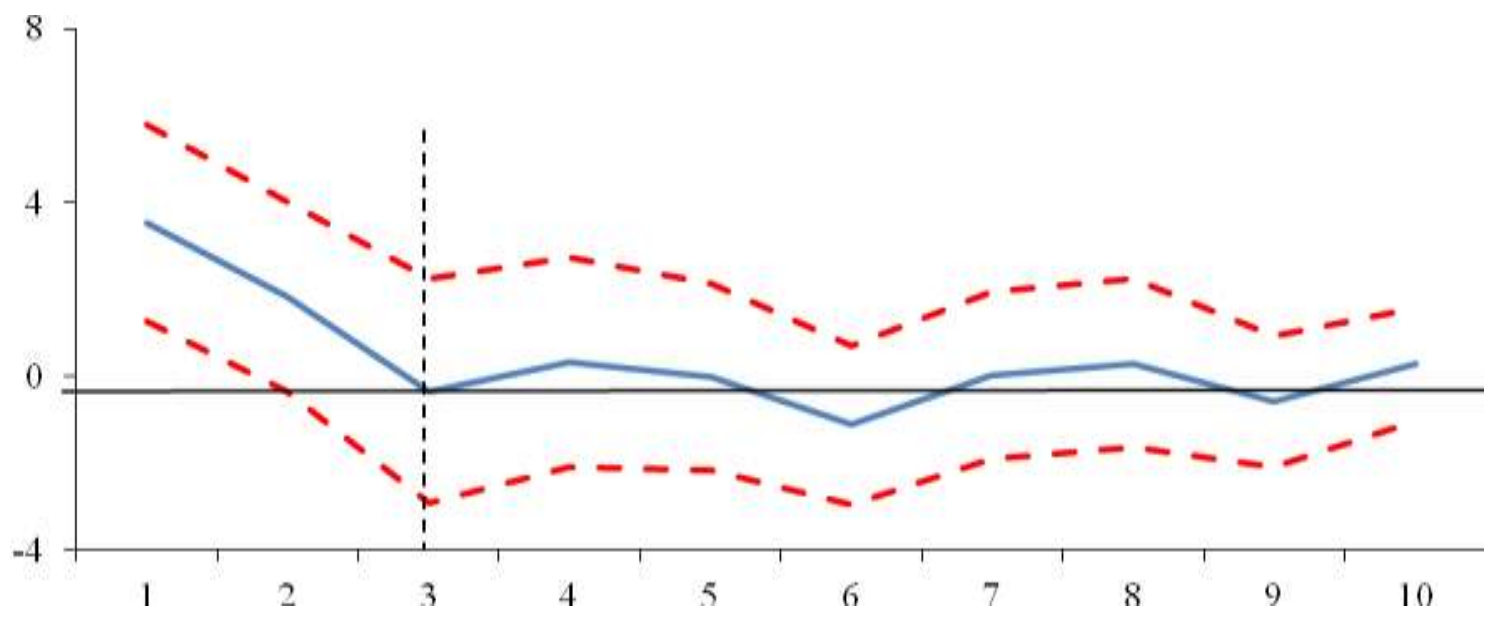

Figura 3. Análisis de impulso-respuesta: respuesta de la tasa de crecimiento del PIB del sector del sector de la construcción al impulso de la tasa de crecimiento del flujo de las remesas, 2004.1-2013.4 
Fuente: Elaboración propia a partir de los datos de CAMACOL y Banco de la República (2014).

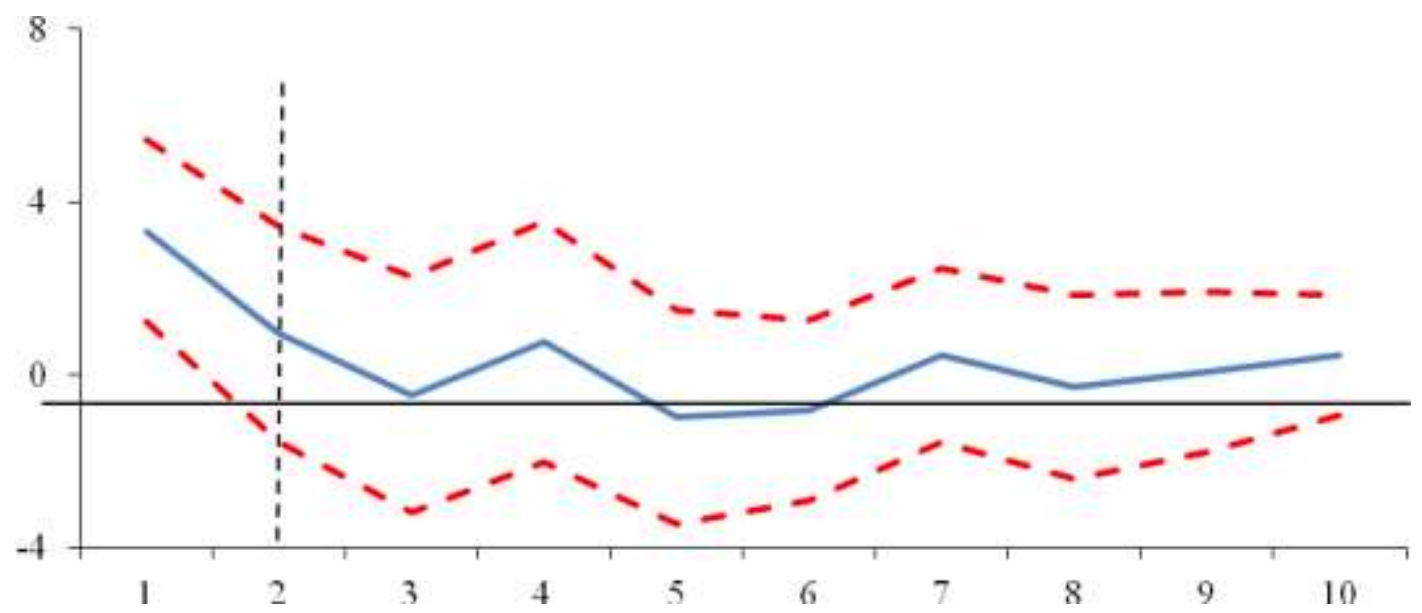

Figura 4. Análisis de impulso-respuesta: respuesta de la tasa de crecimiento del flujo de las remesas al impulso de la tasa de crecimiento del PIB del sector de la construcción, 2004.1-2013.4

Fuente: Elaboración propia a partir de los datos de CAMACOL y Banco de la República (2014).

El análisis de descomposición de varianza (véase tabla 5 del anexo estadístico) es un complemento del análisis de impulso-respuesta, ya que registra el porcentaje de volatilidad de una variable por los choques causados por las demás series consideradas, Loría (2007: 314).

Los principales resultados indican el peso y la importancia del crecimiento de las remesas $(\Delta \mathrm{Rem})$ en el crecimiento del producto de la construcción, ya que la primera explica casi $28 \%$ de la variación porcentual de $(\Delta \mathrm{Co})$, lo cual nos permite complementar la comprobación de la hipótesis de estudio. Dicho porcentaje de impacto es importante, debido a que, si bien la evolución del producto del sector de la construcción puede depender de diversos factores, en este caso se analiza el impacto de las remesas en dicho sector, por lo tanto, que casi treinta por ciento de la variación sea explicado por el flujo monetario enviado por los migrantes, refleja que efectivamente, el fomento de la adquisición de viviendo —ó las remodelaciones en las viviendas propias - resultaron con efectos sumamente positivos para impulsar la tendencia creciente del sector de la construcción. Por otro lado, se encuentra un efecto autorregresivo importante del crecimiento de las remesas $(\Delta \mathrm{Rem})$, en virtud, que después de 30 periodos el $98 \%$ de la varianza es explicada por sí misma, ya que prácticamente toda la innovación de las remesas se debe a cambios en esta misma variable; mientras que tan sólo 2\% 
corresponde al crecimiento del producto del sector de la construcción $(\Delta \mathrm{Co})$ lo que demuestra el poco peso de $\Delta$ Co en $\Delta$ Rem.

Para observar la capacidad de réplica del modelo, con el algoritmo Gauss-Seidel obtenemos la simulación del sistema, en la cual se puede establecer una aproximación al Proceso Generador de Información (PGI), que es el mecanismo que genera la información que se observa.

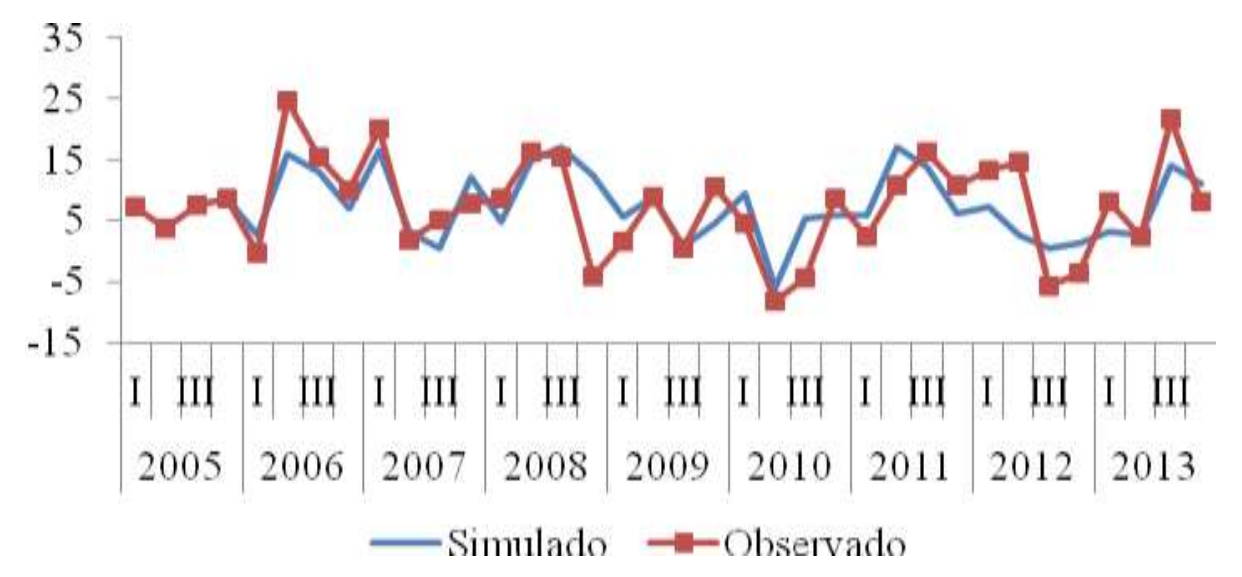

Figura 5. Simulación histórica de la tasa de crecimiento del PIB del sector de la construcción, 2005.1-2013.4

Fuente: Elaboración propia a partir de los datos de CAMACOL y Banco de la República (2014).

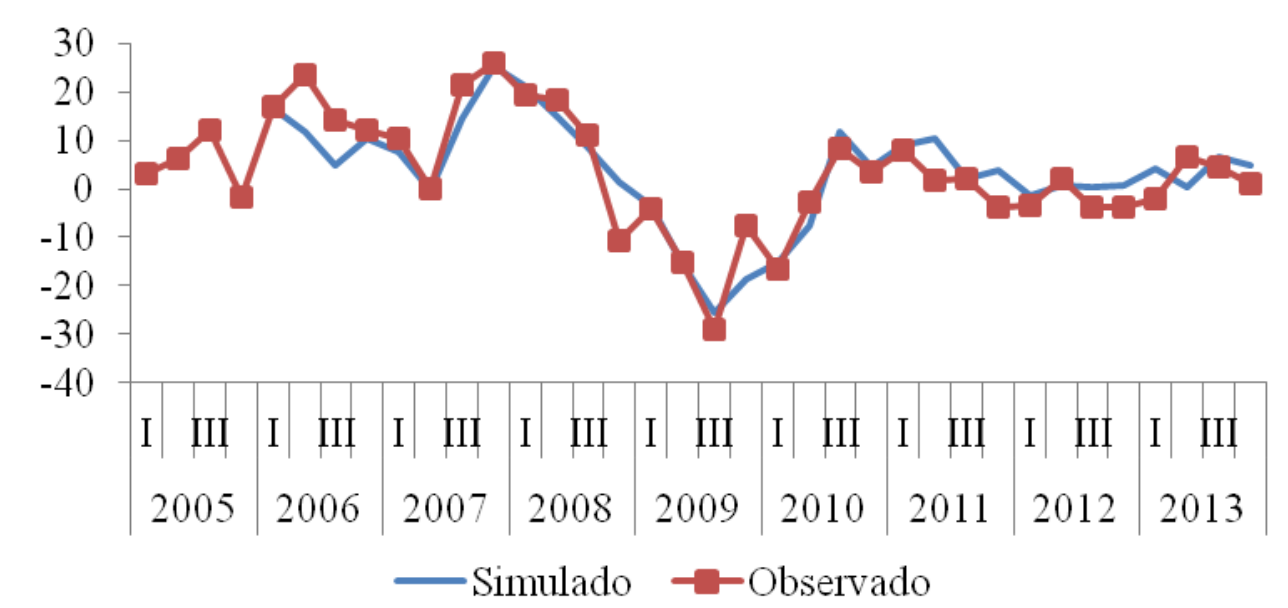

Figura 6. Simulación histórica de la tasa de crecimiento del flujo de las remesas, 2005.1-2013.4

Fuente: Elaboración propia a partir de los datos de CAMACOL y Banco de la República (2014). 
A través de las figuras 5 y 6 se comprueba que la estimación econométrica replica el comportamiento real (observado) de las tasas de crecimiento del flujo de las remesas y del PIB del sector de la construcción, lo cual permite confirmar las inferencias económicas realizadas.

\section{Discusión o Conclusiones}

La crisis económica a finales de la década de los noventa en Colombia constituyó la génesis de un fuerte proceso migratorio que trajo consigo un incremento en el flujo de las remesas, que a su vez constituyeron una fuente importante de ingresos en términos agregados para el país. Bajo dicho contexto, el Gobierno de la República de Colombia promocionó el sector de la construcción — tanto de las obras civiles como las edificaciones-, a través de ciertas políticas incluidas en los Planes Nacionales de Desarrollo, con el objetivo, entre otros, de poder encauzar las remesas hacia dicho sector e incentivar la inversión inmobiliaria de ciudadanos colombianos residentes en el exterior.

Por lo tanto, para comprobar cuál es el tipo de impacto del flujo de las remesas captadas por Colombia, sobre el PIB del sector de la construcción, se estimó para el periodo 2004.1-2013.4 un modelo de Vectores Autorregresivos Irrestricto, los resultados obtenidos nos permiten deducir que el entorno económico, produjo que los ingresos por remesas impactaran de forma procíclica al comportamiento de la tasa de crecimiento del producto del sector de la construcción. De tal forma, estos hallazgos podrían indicar que el conjunto de políticas públicas coadyuvaron a que los migrantes tuvieran incentivos para incrementar el flujo de las remesas para la adquisición de activos fijos en el país.

A su vez, las funciones impulso-respuesta muestran efectos positivos del crecimiento del flujo de las remesas al crecimiento del PIB del sector de la construcción y viceversa, dados choques positivos sobre ambas variables. Además, a través del análisis de la descomposición de varianza, se encuentra que la tasa de crecimiento de las remesas explica $28 \%$ de la varianza del producto del sector de la construcción durante el periodo de análisis. 
En general, se establece que si bien el monto de las remesas se han expandido fuertemente después del año 2000, en gran medida por el importante flujo de migrantes colombianos al exterior, el análisis que hemos realizado no sólo se ubica entre la visión funcionalista (dirigir las remesas a inversiones productivas del país receptor) sino que también han sido las políticas gubernamentales —como lo sugiere el tercer y más reciente enfoque de estudio de las remesas en América Latina- que permitieron dirigir dichas divisas al sector de la construcción. Sin embargo, es evidente que ante la actual situación económica en España y la fragilidad de la economía de Estados Unidos (principales destinos de los migrantes colombianos), las políticas públicas debieran tener como otro de sus objetivos, impulsar el sector industrial o el desarrollo de infraestructura productiva nacional, en la búsqueda de un relanzamiento del mercado interno que se traduzca en ampliar empleos formales en el mediano y largo plazo, ya que ante la fragilidad de los mercados laborales donde se ubican los migrantes colombianos, es posible que el flujo de las remesas disminuya, lo que consecuentemente podría generar ciertos efectos negativos (como la contracción del ingreso familiar), por lo tanto, se debe procurar que dichos efectos sean lo menos negativos ante un escenario de reiterada crisis económica mundial como la ya presentada en 2008-2009.

\section{Referencias}

Banco Mundial (2011). Datos sobre migración y remesas 2011. Recuperado de http://siteresources.worldbank.org/INTPROSPECTS/Resources/334934-

\section{$\underline{1110315015165 / \text { Factbook2011Spanish.pdf }}$}

Banco de la República (2014). Encuesta Trimestral de Remesas. Revisado el 19 de mayo de 2014. Recuperado de http://www.banrep.gov.co/es/remesas

Brown, S.S. (2006). Can remittances spur development? A critical survey. International Studies Review, 8(1), 55-76.

Bouhga-Hagbe, J. (2006). Altruism and workers' remittances: Evidence from selected countries in the Middle East and Central Asia. International Monetary Fund, 06(130), 1-27.

CAMACOL (2008). El sector de la construcción en Colombia: hechos estilizados y principales determinantes del nivel de actividad. Recuperado de http://camacol.co/sites/default/files/secciones_internas/EE_Inv20081119101141 - 
CAMACOL (2011). Entendiendo el PIB de edificaciones. Recuperado de http://camacol.co/sites/default/files/secciones_internas/Informe\%20econ\%C3\% B3mico\%20marzo\%202011_1.pdf

CAMACOL (2014). Construcción en cifras. Revisado el 20 de mayo de 2014. Recuperado de http://camacol.co/informacion-economica/cifras$\underline{\text { sectoriales/construccion-en-cifras }}$

Cárdenas, M., y Bernal, R. (1997). Auge y crisis de la construcción en Colombia: Causas y consecuencias. Revista Camacol, 1(1), 8-32.

Cárdenas, M., Cadena, X., y Quintero, J.F. (2004). Determinantes de la actividad constructora en Colombia. Recuperado de http://camacol.co/sites/default/files/secciones_internas/EE_Coy20081201052713 $\underline{. p d f}$

Cárdenas, M. y Hernández, M. (2006). El sector financiero y la vivienda. Recuperado de http://www.fedesarrollo.org.co/wp-content/uploads/2011/08/El-SectorFinanciero-y-la-Vivienda-M.-C\%C3\%A1rdenas-y-M.-Hern\%C3\%A1ndez2006.pdf

Carvajal, L., y de Jesús, L. (2011). Remesas y crecimiento: un análisis estructural para México. Análisis Económico, 26(62), 209-228.

CEPAL (2008). Los efectos de las remesas. En J. Martínez (ed.), América Latina y el Caribe: migración internacional, derechos humanos y desarrollo, 185-255. Santiago de Chile: CEPAL

Chami, R., Fullenkamp, C., y Jahjah, S. (2005). Are immigrant remittance flows a source of capital for development? International Monetary Fund, 52(1), 55-81.

DANE (2014). Información Estadística. Revisado el 20 de mayo de 2014. Recuperado de http://www.dane.gov.co/index.php

Díaz, J., Gaitán, F., Piraquive, G., Ramírez, M., y Roda, P. (1993). Dinámica de la construcción entre 1950 y 1991. Planeación y Desarrollo, 24(2), 265-287.

DNP (2003). Impulsar el crecimiento económico sostenible y la generación de empleo.

En S. Montenegro (Dir.). Plan Nacional de Desarrollo 2002-2006. Hacia un Estado Comunitario, 101- 161. Bogotá: DNP

DNP (2010). Crecimiento sostenible y competitividad. En H. Gómez (Dir.). Bases del Plan Nacional de Desarrollo 2010-2014. Prosperidad para todos, 49-247. Bogotá: DNP 
Fajnzylber, P. y López, J. H. (2006). El impacto de las remesas en el desarrollo de América Latina. Washington D.C.: World Bank.

FOMIN (2013). Las Remesas a América Latina y el Caribe 2012: Comportamiento diferenciado entre subregiones. Recuperado de http://idbdocs.iadb.org/wsdocs/getDocument.aspx?DOCNUM=37735670

Gapen, M. T., Barajas, A., Chami, R., Montiel, P., y Fullenkamp, C. (2009). Do Workers' Remittances Promote Economic Growth? International Monetary Fund, 09(153), 3-22.

Granger, C. W. (1969). Investigating causal relations by econometric models and crossspectral methods. Econometrica: Journal of the Econometric Society, 37(3), 424-438.

Greene, W. H. (1999). Análisis econométrico (2 $2^{\mathrm{a}}$ ed). Madrid: Prentice Hall.

Herrera, S. (1988). Notas sobre algunos aspectos del mercado de la edificación en Colombia. Revista Camacol, 41, 16-21.

Khoudour-Castéras, D. (2007). Migraciones internacionales y desarrollo: el impacto socioeconómico de las remesas en Colombia. Revista de la CEPAL, 92, 143-161.

Loría, E. (2007). Econometría con aplicaciones. México: Pearson Prentice Hall.

Lucas, R., y Stark, O. (1985). Motivations to remit: Evidence from Botswana. Journal of Political Economy, 93(5), 901-918.

Martínez, J. (2008). América Latina y el Caribe: migración internacional, derechos humanos y desarrollo. Santiago de Chile: CEPAL.

McBride, B. (2007). Building Capital: the Role of migrant remittances in housing improvement and construction in El Salvador (Tesis de Maestría). Erasmus University Rotterdam. Nederlands.

Ministerio de Empleo y Seguridad Social de España (2014). Estadísticas Observatorio Permanente de la Inmigración. Revisado el 17 de mayo de 2014. Recuperado de http://extranjeros.empleo.gob.es/es/Estadisticas/index.html

Ministerio de Hacienda y Crédito Público (2013). Plan de Impulso a la Productividad y el Empleo (PIPE). Revisado el 24 de abril de 2014. Recuperado de http://www.minhacienda.gov.co/portal/pls/portal/docs/1/9248602.PDF

Ministerio de Relaciones Exteriores de Colombia (2014). Antecedentes históricos y causas de la migración. Revisado el 20 de mayo de 2014. Recuperado de http://www.cancilleria.gov.co/colombia/migration/historical 
Montoya, D., Restrepo, C., Arboleda, P., Ramírez, A., y Viana-Casas, A. (2010). Remesas como instrumento de crecimiento económico en Colombia: remesas y el sector de la construcción en Colombia. Revista de Negocios Internacionales, 3(2), 64-86.

OIM (2013). Perfil Migratorio de Colombia 2012. Recuperado de https://www.iom.int/files/live/sites/iom/files/pbn/docs/Perfil-Migratorio-deColombia-2012.pdf

Pesaran, H. H., y Shin, Y. (1998). Generalized impulse response analysis in linear multivariate models. Economics letters, 58(1), 17-29.

Ratha, D. (2005). Workers' remittances: An important and stable source of external development finance. En The World Bank (ed.), Global Development Finance 2003, 157-175. Washington D.C: The World Bank.

Sayan, S. (2006). Business cycles and workers' remittances: How do migrant workers respond to cyclical movements of GDP at home? International Monetary Fund, 06(52), 1-19.

Sims, C. A. (1980). Macroeconomics and reality. Econometrica, 48(1), 1-48.

Torres, T. (2011). El sector de la construcción: motor de la economía. Recuperado de http://www.utpl.edu.ec/comunicacion/wp-content/uploads/2012/12/utplInforme-de-coyuntura-economica-N-6-ano-2011.pdf

Uribe, J. (2005). Remesas de trabajadores y su impacto económico. Revista del Banco de la República, 78(938), 1-17.

Urrutia, M. (2003). La Importancia de las Remesas de Trabajadores para el Crecimiento Económico y su Evolución Reciente en Colombia. Revista del Banco de la República, 76(910), 5-27.

Zapata, G. P. (2011, junio). The migration-remittances-development nexus: 'Mi casa con Remesas' and transnational flows between Colombia and London. Conferencia presentada en la Universidad de Trento, Italia. Recuperado de http://www.unibielefeld.de/tdrc/ag_comcad/downloads/Workingpaper_106_Zap ata.pdf 


\section{Anexo estadístico}

5.1 Pruebas de raíces unitarias y descomposición de la varianza, 1995-2013.

Tabla 4. Pruebas de raíces unitarias, 1995-2013

Variables

KPSS Dickey-Fuller GLS (ERS)

\begin{tabular}{|c|c|c|}
\hline \multirow[t]{2}{*}{ Rem } & $0,14^{A}$ & $-1,72^{\mathrm{A}}$ \\
\hline & $0,27^{\mathrm{B}}$ & $-1,03^{\mathrm{B}}$ \\
\hline \multirow[t]{2}{*}{$\Delta$ Rem } & $0,10^{\mathrm{A}}$ & $-3,64^{A}$ \\
\hline & $0,27^{\mathrm{B}}$ & $-1,75^{\mathrm{B}}$ \\
\hline \multirow[t]{2}{*}{ PIB } & $0,15^{\mathrm{A}}$ & $0,02^{\mathrm{A}}$ \\
\hline & $0,56^{\mathrm{B}}$ & $-1,48^{\mathrm{B}}$ \\
\hline \multirow[t]{2}{*}{$\Delta \mathrm{PIB}$} & $0,09^{\mathrm{A}}$ & $-3,21^{A}$ \\
\hline & $0,33^{\mathrm{B}}$ & $-2,82^{\mathrm{B}}$ \\
\hline \multirow[t]{2}{*}{ Rem } & $0.17^{\mathrm{A}}$ & $9,62^{\mathrm{A}}$ \\
\hline & $0,31^{\mathrm{B}}$ & $7,31^{\mathrm{B}}$ \\
\hline \multirow[t]{2}{*}{$\Delta$ Rem } & $0,08^{\mathrm{A}}$ & $-2,93^{A}$ \\
\hline & $0,27^{\mathrm{B}}$ & $-2,66^{\mathrm{B}}$ \\
\hline \multirow[t]{2}{*}{ Co } & $0,08^{\mathrm{A}}$ & $-0,44^{\mathrm{A}}$ \\
\hline & $\mathbf{0 , 7 6 ^ { \mathrm { B } }}$ & $-5,07^{\mathrm{B}}$ \\
\hline \multirow[t]{2}{*}{$\Delta \mathrm{Co}$} & $0,07^{\mathrm{A}}$ & $-5,12^{A}$ \\
\hline & $0,11^{\mathrm{B}}$ & $-5,08^{B}$ \\
\hline
\end{tabular}

Nota: Rem $=$ Flujo de las remesas; $\Delta$ Rem $=$ Tasa de crecimiento del flujo de las remesas; PIB = Producto Interno Bruto total; $\triangle \mathrm{PIB}=$ Tasa de crecimiento del PIB total; $\mathrm{Co}=\mathrm{PIB}$ del sector de la construcción; $\Delta \mathrm{Co}=$ Tasa de crecimiento del PIB del sector de la construcción. Modelo A (constante y tendencia), modelo B (constante), modelo C (sin constante y sin tendencia). Rechazo de la hipótesis nula de que existe raíz unitaria en negritas para la prueba Dickey-Fuller GLS (ERS), los estadísticos de KwiatkowskiPhillips-Schmidt- Shin (KPSS) la hipótesis nula considera que la serie es estacionaria. Todas las pruebas son válidas al $95 \%$ de confianza.

Fuente: Elaboración propia a partir de los datos de CAMACOL y Banco de la República (2014). 
Tabla 5. Descomposición de varianza, 2004.1-2013.4

\begin{tabular}{cccc}
\hline \multicolumn{4}{c}{ Descomposición de la varianza de $\Delta$ Rem } \\
\hline Periodo & Desviación Estándar & $\Delta$ Rem & $\Delta$ Co \\
\hline 1 & 6,42 & 100,00 & 0,00 \\
5 & 7,15 & 98,77 & 1,24 \\
10 & 7,40 & 98,26 & 1,74 \\
15 & 7,42 & 98,08 & 1,92 \\
20 & 7,42 & 98,07 & 1,93 \\
25 & 7,43 & 98,07 & 1,93 \\
30 & 7,43 & 98,07 & 1,93 \\
\hline & Descomposición de la varianza de $\Delta$ Co & \\
\hline Periodo & & & \\
& Desviación Estándar & $\Delta$ Rem & $\Delta$ Co \\
\hline 1 & 6,86 & 26,65 & 73,35 \\
5 & 7,79 & 26,57 & 73,43 \\
10 & 8,06 & 27,54 & 72,46 \\
15 & 8,11 & 27,65 & 72,35 \\
20 & 8,12 & 27,70 & 72,30 \\
25 & 8,13 & 27,70 & 72,30 \\
30 & 8,13 & 27,70 & 72,30 \\
\hline
\end{tabular}

Fuente: Elaboración propia a partir de los datos de CAMACOL y Banco de la República (2014). 
5.2 Diagrama de dispersión, 1995-2013.
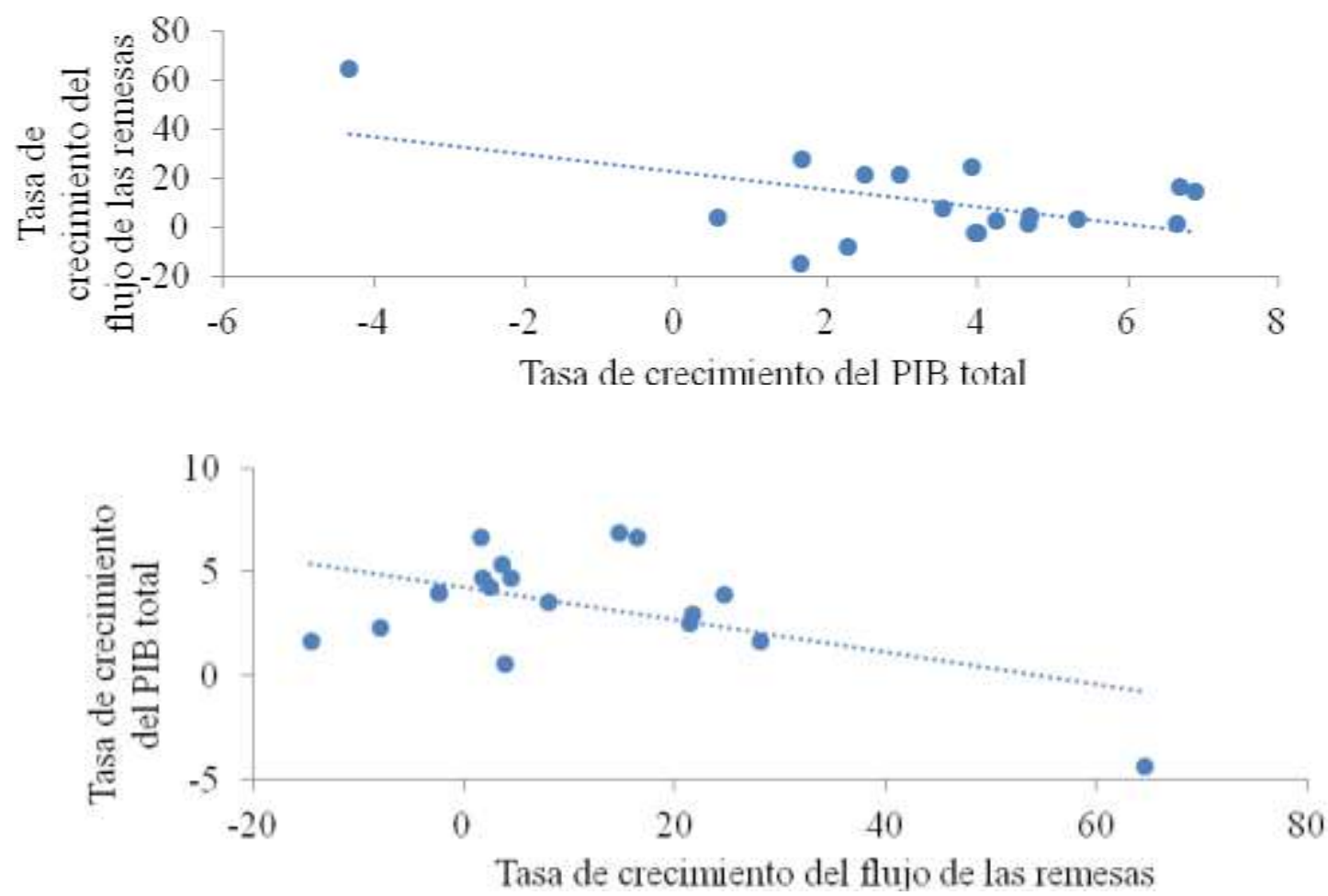

Figura 7. Diagrama de dispersión: tasa de crecimiento del PIB total vs tasa de crecimiento del flujo de las remesas, $1995-2013^{5}$

Fuente: Elaboración propia con datos del Banco de la República (2014).

${ }^{5} \mathrm{r}=-0,52 ; \mathrm{t}=-2,48$ 